\title{
Comparison of Crushed-Zone Skin Factor for Cased and Perforated Wells Calculated with and without including a Tip-Crushed Zone Effect
}

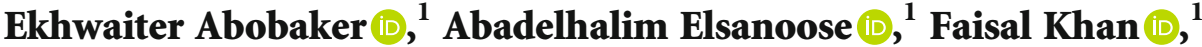 \\ Mohammad Azizur Rahman ${ }^{(D},{ }^{2}$ Amer Aborig, ${ }^{1}$ and Stephen Butt ${ }^{1}$ \\ ${ }^{1}$ Memorial University of Newfoundland, St. John's NL, Canada \\ ${ }^{2}$ Texas A\&M University at Qatar, Doha, Qatar
}

Correspondence should be addressed to Ekhwaiter Abobaker; eera48@mun.ca

Received 7 April 2021; Accepted 21 June 2021; Published 19 July 2021

Academic Editor: Mohammad Sarmadivaleh

Copyright (C) 2021 Ekhwaiter Abobaker et al. This is an open access article distributed under the Creative Commons Attribution License, which permits unrestricted use, distribution, and reproduction in any medium, provided the original work is properly cited.

\begin{abstract}
A number of different factors can affect flow performance in perforated completions, such as perforation density, perforation damage, and tunnel geometry. In perforation damage, any compaction at the perforation tunnels will lead to reduced permeability, more significant pressure drop, and lower productivity of the reservoir. The reduced permeability of the crushed zone around the perforation can be formulated as a crushed-zone skin factor. For reservoir flow, earlier research studies show how crushed (compacted) zones cause heightened resistance in radially converging vertical and horizontal flow entering perforations. However, the effects related to crushed zones on the total skin factor are still a moot point, especially for horizontal flows in perforations. Therefore, the present study will look into the varied effects occurring in the crushed zone in relation to the vertical and horizontal flows. The experimental test was carried out using a geotechnical radial flow set-up to measure the differential pressure in the perforation tunnel with a crushed zone. Computational fluid dynamics (CFD) software was used for simulating pressure gradient in a cylindrical perforation tunnel. The single-phase water was radially injected into the core sample with the same flow boundary conditions in the experimental and numerical procedures. In this work, two crushed zone configuration scenarios were applied in conjunction with different perforation parameters, perforation length, crushed zone radius, and crushed zone permeability. In the initial scenario, the crushed zone is assumed to be located at the perforation tunnel's side only, while in the second scenario, the crushed zone is assumed to be located at a side and the tip of perforation (a tip-crushed zone). The simulated results indicate a good comparison with regard to the two scenarios' pressure gradients. Furthermore, the simulations' comparison reveals another pressure drop caused by the tip crushed zone related to the horizontal or plane flow in the perforations. The differences between the two simulations' results show that currently available models for estimating the skin factor for vertical perforated completions need to be improved based on which of the two cases is closer to reality. This study has presented a better understanding of crushed zone characteristics by employing a different approach to the composition and shape of the crushed zone and permeability reduction levels for the crushed zone in the axial direction of the perforation.
\end{abstract}

\section{Introduction}

For cased hole completions, the well needs to be perforated in order for communication to be enabled between the formation and wellbore. This is because perforations enhance flow convergence at the near-wellbore region. In comparison with ideal open-hole wells, perforated wells can undergo added pressure gains and losses. Especially when a well has a short length of perforations with lower density, it may lead to a greater drop in pressure at the near-wellbore region, which will lower the overall well productivity. Moreover, when wells are perforated by deep penetrating tunnels, there may be a 
more expansive communication area between the formation and the perforated wells. When this occurs, the perforations might enhance well productivity due to less pressure drop.

Any added pressure gain or drop that is due to ideal perforation may be formulated as a perforation pseudoskin factor. In this case, this skin factor is related to parameters like wellbore diameter, perforation length, shot density, and phasing angle. Note that during the perforation process, rocks at the perforation tunnels' sites are crushed. However, the perforation pseudoskin factor measures flow convergence at perforations in ideal perforated wells, neglecting the effect of the crushed (compacted) zone encircling the perforation tunnels. Experimental data indicate that the greatest contribution to total skin is the crushed zone, whereas formation damage skin and perforation pseudoskin make less contribution overall. Furthermore, based on studies (i.e., field and experimental) conducted over the past half-century, a major factor adversely affecting productivity is deficiencies in perforating procedures, perforator design, or both. For example, some studies on perforation damage showed that productivity declined in a gun-perforated hole formation when shots were fired into solid-containing fluid, such as drilling muds. There was also decreased productivity in cases where wellbore pressure exceeded formation pressure. In a typical process of perforation, a low-conductivity hole is created in the damaged formation. Postperforation, the crushed damage expands around the perforation radially from the center of the perforation tunnel. In this evolution, compacted and pulverized rock and other debris from a barrier block the formation's natural pore spaces. Figure 1 illustrates this process [1-3].

The earlier studies mentioned above showed the importance of clearing perforating debris away from perforations to optimize the flow capacity. Debris removal, whether of some or most of the damaged material, enables the perforation tunnel to better perform its role as the wellbore's fluid conduit. One highly efficient way to remove the debris is through underbalanced perforating, although the precise underbalance degree required for generating effective perforations is still a topic of debate. The underbalance is usually calculated by considering the matrix permeability, along with tunnel parameters and fluid, as described by Tariq [4], Walton [5], and Grove et al. [6]. More recent research has looked into various aspects of cleanup and productivity mechanisms in relation to perforation tunnels. Several studies have used computational analysis, due to a lack of experimental data, to explore a number of different challenges, such as isolating the competing effects of debris cleanup and dealing with the heterogeneity that often characterizes analog cores. One of the research teams who used the computational approach is Satti et al. [7-9]; they proposed a 3-D flow model to determine flow impediments based on characteristics of perforation damage, debris and blockages, and tunnel geometry. The authors used the latest micro-CT methods as well as simulations to determine the most viable cleanup strategies for optimal productivity.

Interactions between formation damage, flow convergence near perforation tunnels, and rock compaction need to be carefully formulated; rock compaction and formation

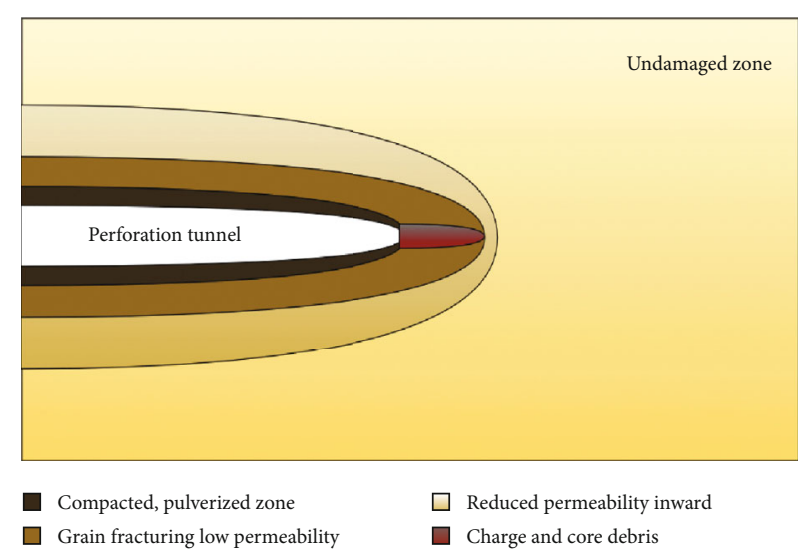

Figure 1: Schematic diagram of the crushed zone around the perforation.

damage can create a higher degree of dynamic interaction between plane flow and flow convergence at the perforations. The effects of rock compaction and formation damage should thus be included in any perforation model that is developed. However, these interactions can be extremely complex in nature, particularly when including parameters such as mechanical skin factor (formation damage), ideal perforation pseudoskin factor, and crushed-zone skin factor. Overall, perforation total skin factor $\left(S_{p d c}\right)$ can be used to represent the combined impacts of reductions in compaction zone permeability near perforation tunnels, ideal perforations, and formation damage caused by drilling and other production operations near wellbores. In the Darcy flow case, any other pressure changes caused by these impacts in combination may be written as

$$
\Delta p_{p d c}=\frac{Q \mu}{2 \pi k_{f} h} S_{p d c} .
$$

A wide range of models (empirical, numerical, experimental, semianalytical, etc.) have been developed over the past several decades for predicting perforated total skin and for determining the effects of the crushed zone. For example, Klotz et al. [10] employed a 2-D finite element model to examine how perforations and formation damage at the crushed zone affect well productivity, while Locke [11] looked at a novel way (nomograph) to estimate skin for perforated completions. Nomographs can take skin factors into account by considering rock compaction and formation damage at perforation tunnels. The nomograph results can be integrated into models that measure well performance. A decade later, in a study conducted by Thomas et al. [12], a table look-up procedure was used for combining the results of Locke's nomograph and software developed for well performance. McLeod [13] suggested that the combined effects of rock compaction, formation damage, and perforation pseudoskin at perforation tunnels could be captured in Equation (2), as written below:

$$
S_{p d c}=s_{d}+s_{p}+s_{c z}
$$


The crushed-zone skin factor is expressed in

$$
s_{c z}=\frac{h}{L_{p} n}\left(\frac{k_{f}}{k_{c z}}-\frac{k_{f}}{k_{d}}\right) \ln \left(\frac{r_{c z}}{r_{p}}\right) \text {. }
$$

Using a finite element simulator, Karakas and Tariq [14] formulated several empirical equations for predicting total skin factor at fully perforated vertical wells. One example of their formulations was an equation that predicted perforation pseudoskin in cases where there was no drilling damage.

$$
S_{p d c}=s_{h}+s_{v}+s_{w b}+s_{c z}
$$

In this equation, the initial term indicates flow convergence in the horizontal plane, the second term denotes flow convergence in the vertical plane, and the third term describes the effect of the wellbore geometry. The researchers also employed a formulation somewhat like Equation (3) above to express the crushed-zone skin factor $S_{c z}$. This formulation is written as Equation (5) below:

$$
s_{c z}=\frac{h}{L_{p} n}\left(\frac{k_{f}}{k_{c z}}-1\right) \ln \left(\frac{r_{c z}}{r_{p}}\right) \text {. }
$$

In other related research, Bell et al. [15] formulated a skin factor equation to account for perforations that ended within the confines of drill-damaged zones. This formula was based on the previous Karakas and Tariq model [14] mentioned earlier and considered formation damage and crushed zone effects in combination. In 2006, Yildiz [16] proposed a novel way to assess total skin factor that accounted for a large number of other factors, including compaction zone skin, perforation pseudoskin, drill-damaged skin, and the impact of partial formation perforation. However, despite their achievements, the effects related to crushed zones on the total skin factor are still a moot point, especially for horizontal flows in perforations. Also, computational fluid dynamics (CFD) investigations have been conducted by Sun. et al. [17] for a perforated vertical well with different crushed zone scenarios. Their results showed an apparent discrepancy between the supposed crushed zone scenarios and available models.

All the preceding factors have derived several models based on the assumption that a crushed zone is uniform and cylindrical and has a homogeneous permeability and porosity. At the same time, recent studies using modern techniques computerized tomography (CT) and a scanning electron microscope (SEM)) have shown a different perception of the composition and shape of the crushed zone, especially in the axial direction of the perforation tunnel. In recent studies, the researchers have analyzed the results obtained based on the perforation process's effect. The process of perforation involves shooting a perforation agent into the near-wellbore formation to make holes. However, during this process, the affected rock could experience grain bond breakages in addition to microfractures caused by shock waves [18]. Four levels of damage (i.e., four permeability and porosity change zones) were found in each of the simulated cases when per-

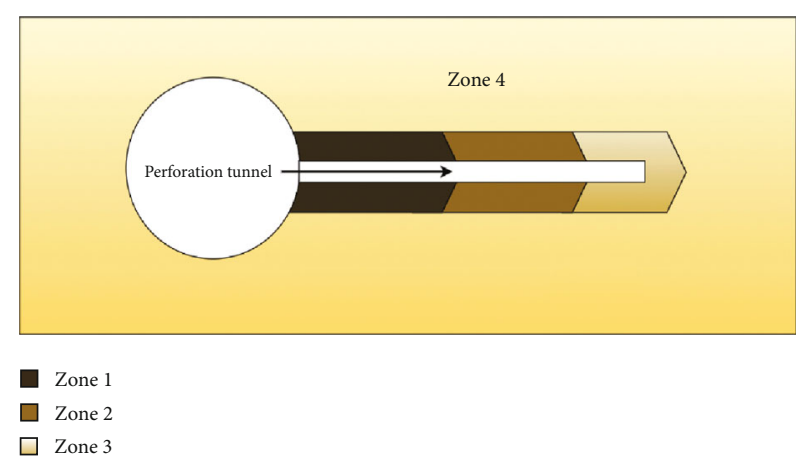

FIGURE 2: Schematic of four different zones of crushed change zones in the axial direction of the perforation tunnel.

meability changes, porosity, and bond breakage in the axial direction and vicinity of the perforation tunnel. In Zone 1, there was a significant and rapid decrease in porosity after the minimum value was achieved. The force of the shock wave in this zone was sufficient to sever every bond between particles. The rocks typically had numerous microcracks, which became angular fragments during backward grain displacement. The result of this process was a major reduction in permeability due to the closing of pore throats. Zone 2 featured less variation in porosity compared to Zone 1. Even though most of the particle bonds in Zone 2 broke, a small portion of the grains did stay intact. Furthermore, after achieving a minimum value, both permeability and porosity saw slower increases in Zone 2 in comparison with Zone 1. In Zone 3, there were overall fewer decreases in permeability and porosity compared to Zones 1 and 2 . Also, in Zone 3, the permeability and porosity generally stayed constant postperforation. The reason for these differences between Zone 3 and Zones 1 and 2 is that the force of the shock wave was attenuated prior to arriving at Zone 3. Moreover, even though many bonds broke in Zone 3, the grains stayed intact. From this, we can see that the porosity decrease in Zone 3 was likely caused by particle adjustment, where the particles stay constant due to forces from particles situated around them. In Zone 4, no bond breakage or porosity damage was detectable, as this zone is too far away for the shock wave to reach, leaving the rock matrix intact. Figure 2 illustrates the four mentioned crushed change zones described by Sarmadivaleh et al. [19], Pucknell and Behrmann [20] Nabipour et al. [21], and Craddock et al. [22].

In addition, Xue et al. [23] developed a mechanical model to describe influences of perforating damage, especially with regard to perforations caused by explosions affecting the permeability and porosity of sandstone at the compaction zone. Their study results indicated that there was a notable decrease in damage, particularly to the thickness of the sandstone, when the load and pressure decreased in the axial direction of perforation tunnel, and these results confirm Sarmadivaleh et al.'s [19] and others' conclusions.

In addressing this research gap, the present study was conducted experimental and numerical investigations by employing a different approach to the composition and shape of the crushed zone and permeability reduction levels for the crushed zone in the axial direction of the perforation. 


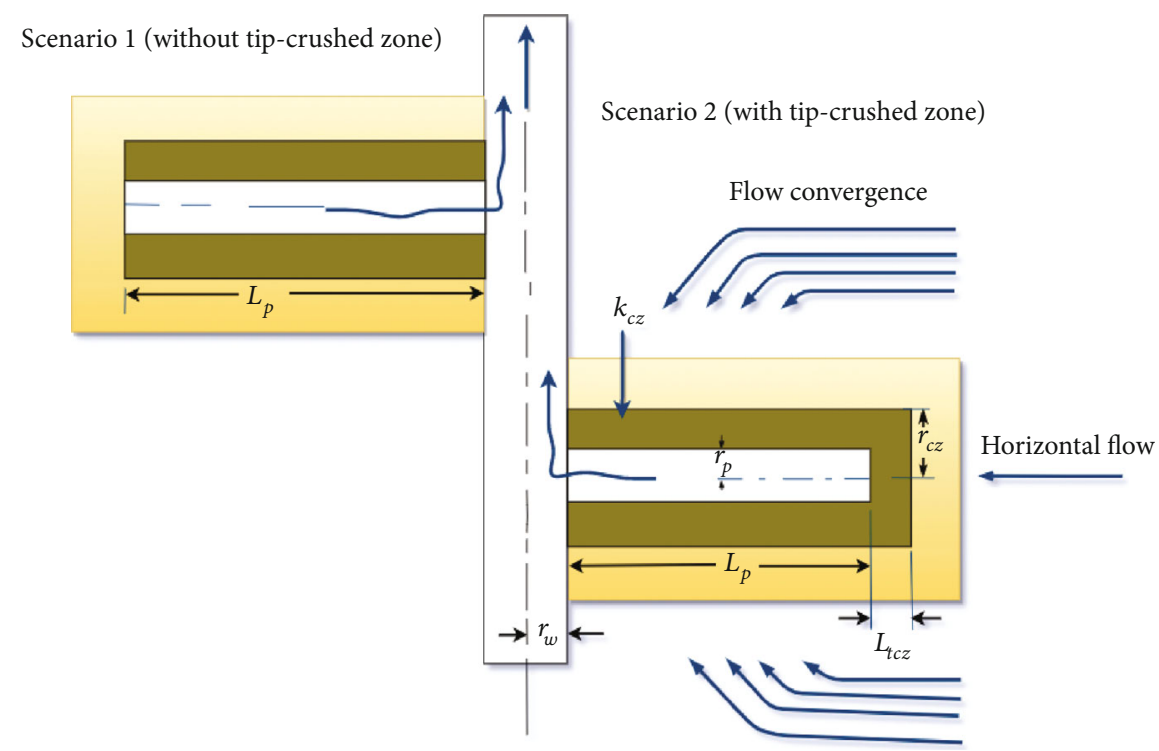

Figure 3: The schematic diagram shows the two scenarios.

The two crushed zone configuration scenarios were applied in conjunction with different perforation parameters, perforation length, crushed zone radius, and crushed zone permeability. In the initial scenario, the perforation zone's tip is assumed to be too far away for the shock wave to reach, leaving the rock matrix intact, so the crushed zone is located at the perforation tunnel's side. In the second scenario, the force of the shock wave in the perforation zone's tip is considered to be sufficient to sever every bond between particles, so the crushed area is located at a side and tip of perforation. The two scenarios are applied in conjunction with different perforation parameters, perforation length, crushed zone radius, and a permeability ratio. In additional investigations, the effect of permeability anisotropy in crushed zones on the crushed skin factor has been studied considering these scenarios.

\section{Methodology}

2.1. Experimental Procedure. The experimental study was used to validate the numerical model for single-phase flow through the perforation tunnel that includes two different permeability zones. The first region surrounds the perforations and represents the crushed zone with low permeability; the second region exemplifies the formation region with high permeability. Statistical analysis was coupled with numerical simulation to expand the investigation of fluid flow in the near-wellbore region due to the limitations of the experimental setup, especially the small sample size. In the study, two crushed zone configuration scenarios are conducted in conjunction with different perforation parameters, perforation length, crushed zone, and permeability ratio, as shown in Figure 3.

In the present study, the experimental set-up initially designed and built by Ahammad et al. $[24,25]$ as a radial flow cell (RFC). The RFC, which was constructed at Memorial University of Newfoundland's Drilling Technology Lab, was created for the purpose of carrying out experiments under wellbore conditions. Figure 4 shows the set-up, which features the three following main sections: flow lines extending from inlet to outlet, an inner chamber for holding samples with axial loads, and a data acquisition (DAQ) system.

In the laboratory experiments, a highly permeable synthetic sandstone sample was prepared. The cylindrical sample was made of sand particles measuring 0.18 to $1.18 \mathrm{~mm}$. The synthetic sample has been created from two different sandstone grain sizes. The fine grain size used to create a crushed zone around the perforation and the coarse grain size used to create a formation reservoir zone are demonstrated in Figure 5. The dimensions and the index properties of the sample included permeability and porosity, as shown in Table 1.

Experiments carried out on perforation methods have primarily relied on rather simplistic assumptions, such as those presented by Rahman et al. [26-30]. Moreover, as a result of laboratory constraints, most experimental investigations have neglected key reservoir characteristics, such as thermal effects, drawdown pressure, and actual reservoir pressure. In the experimental portion of our work, we injected a measured volume of water into our core sample. Also, we used a geotechnical radial flow test set-up to measure the differential pressure and single-phase flow rate of our synthetic sandstone sample, with water being radially injected into our core sample within Darcy flow and flow boundary conditions $(Q=1 \mathrm{~L} / \mathrm{min}, v=0.95 \mathrm{mPa} \cdot \mathrm{s})$. The outer side of the sample is considered an inlet while the perforation surface is an outlet. Furthermore, both inlet and outlet pressures were measured for our cylindrical samples using a specified water flow rate.

2.2. Numerical Procedure. In the present work, we used Ansys Fluent 18.1 for our computational fluid dynamics (CFD) model. Our aim was to present a single-phase fluid flow simulation for a reservoir described as three-dimensional, 


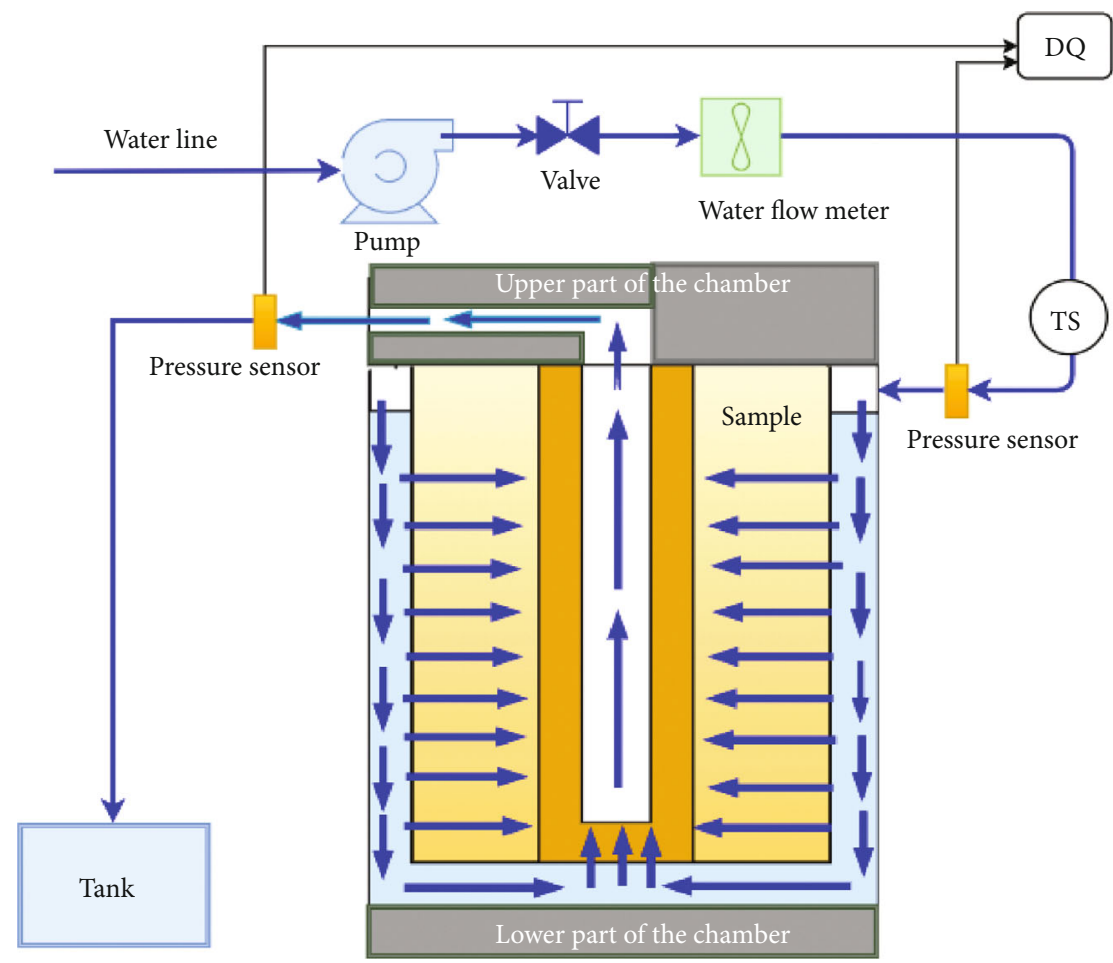

FIGURE 4: Schematic diagram of the experiment: water flow meter, inlet and outlet pressure sensors; TS: temperature sensor; and DAQ: data acquisition system.
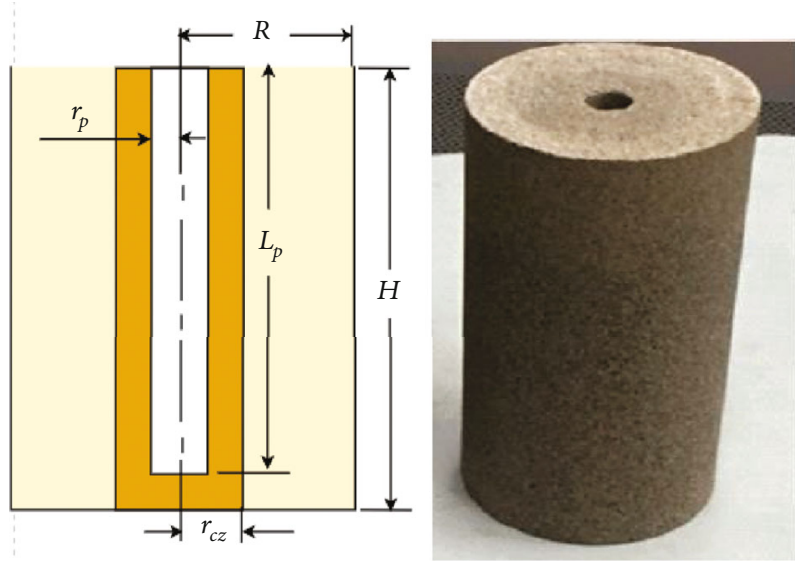

Figure 5: The dimensions of synthetic sandstone sample.

vertical, and cylindrically layered. We created a sample that is vertical with a single layer of uniform thickness $(h)$. Next, we assumed the well was centrally located and had a drilled and casted radius $\left(r_{w}\right)$ throughout the formation. Hence, we could apply the conditions and assumptions enumerated below in developing our model:

(1) The formation is isotropic and porous, of uniform thickness, and is constantly permeable (i.e., features constant vertical permeability that is nonzero)

(2) The flow through the reservoir can be described as single-phase water and either radial-vertical laminar or Darcy's flow
TABLE 1: The dimensions and the index properties of the sample.

\begin{tabular}{lc}
\hline Dimensions and properties the sample & Values (units) \\
\hline Sample height $(H)$ & $30.48 \mathrm{~cm}$ \\
Sample radius $(R)$ & $7.62 \mathrm{~cm}$ \\
Perforation tunnel radius $\left(r_{p}\right)$ & $1.27 \mathrm{~cm}$ \\
Crushed zone radius $\left(r_{c z}\right)$ & $5.08 \mathrm{~cm}$ \\
Perforation length $\left(L_{p}\right)$ & $25.4 \mathrm{~cm}$ \\
Permeability of crushed zone $\left(k_{c z}\right)$ & $6.218 \times 10^{-12} \mathrm{~m}^{2}$ \\
Porosity of skin zone $\left(\gamma_{s}\right)$ & $26 \%$ \\
Permeability of formation zone $\left(k_{f}\right)$ & $2.625 \times 10^{-11} \mathrm{~m}^{2}$ \\
Porosity of formation zone $\left(\gamma_{f}\right)$ & $21 \%$ \\
\hline
\end{tabular}

(3) The liquid is incompressible with a constant viscosity

(4) Any flux proceeding into the well features uniform distribution across perforated intervals

(5) Thermal effects were ignored

(6) The crushed skin has been considered in the present research. Other skin factors and effects of perforations angle, formation permeability anisotropy, and wellbore radius were neglected

The crushed skin factor is affected by crushed zone parameters and the permeability anisotropy of the crushed zone. In contrast, the perforation skin factor is more affected by perforation angle, formation permeability anisotropy, and 


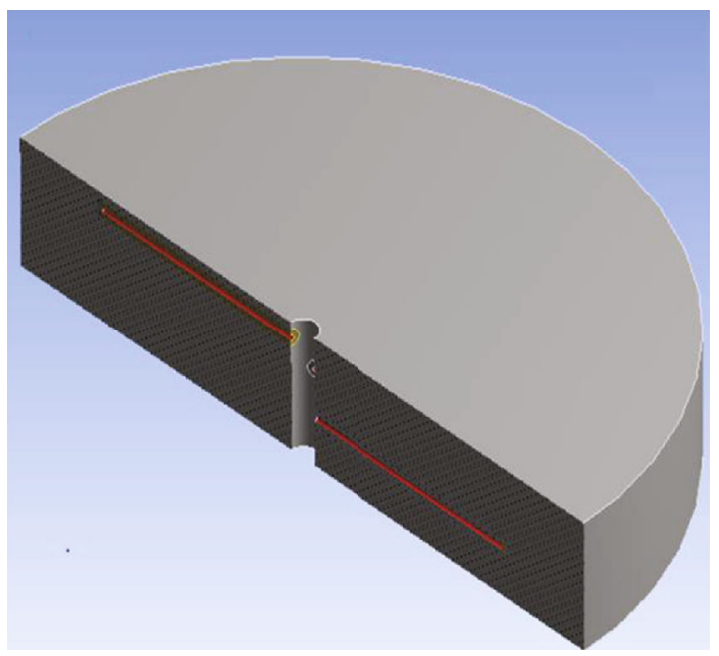

(a)

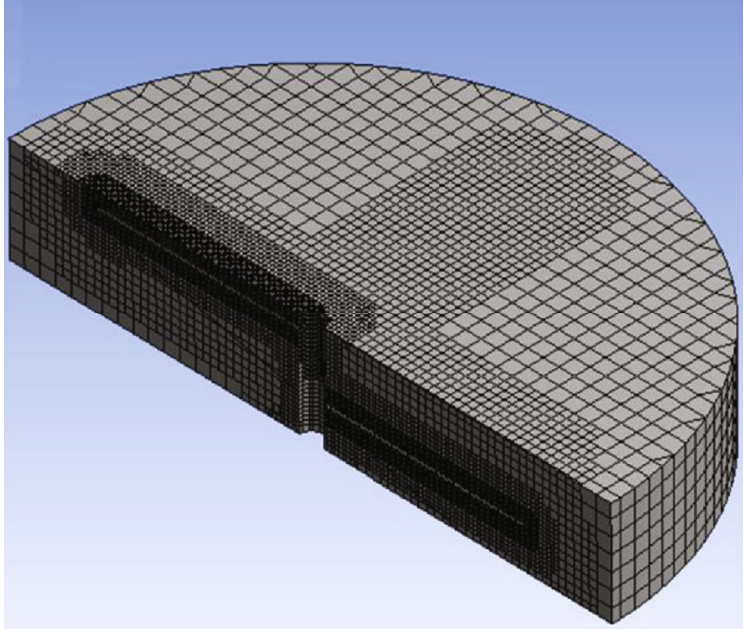

(b)

FIGURE 6: Vertical section shows (a) the outlet and (b) the shape of uniform configuration mesh.

the wellbore radius. Therefore, additional CFD investigations analyzed the effect of permeability anisotropy in crushed zones on the crushed skin factor, considering the study's two mentioned scenarios.

In the numerical work, we injected a measured volume of water into the cylindrical sample. The conservation equations for mass and momentum describing single-phase flow in a porous region could be expressed, respectively, as

$$
\begin{gathered}
\frac{\partial \gamma \rho}{\partial t}+\nabla \cdot(\gamma \rho \vec{v})=0, \\
\frac{\partial}{\partial t}(\gamma \rho \vec{v})+\nabla \cdot(\gamma \rho \vec{v} \vec{v})=- \\
-\left(\frac{\mu}{k} \vec{v}+-\frac{C_{2}}{2} \rho|\vec{v}| \vec{v}\right) .
\end{gathered}
$$

The last term in Equation (7) represents the viscous and inertial loss imposed by the porous media on the fluid. The laminar flows in porous media generally feature a pressure drop proportional to permeability $(k)$ and velocity $(v)$. By ignoring out an inertial loss term, we can reduce the porous media model to Darcy's law, as expressed in

$$
\nabla p=-\frac{\mu}{k} \vec{v}
$$

For the three coordinate directions $(x, y$, and $z)$ of the porous region, the pressure drop calculated by Ansys Fluent can be expressed as in

$$
\begin{aligned}
& \Delta p_{x}=\sum_{j=1}^{3} \frac{\mu}{k_{x j}} v_{j} \Delta n_{x}, \\
& \Delta p_{y}=\sum_{j=1}^{3} \frac{\mu}{k_{y j}} v_{j} \Delta n_{y}, \\
& \Delta p_{z}=\sum_{j=1}^{3} \frac{\mu}{k_{z j}} v_{j} \Delta n_{z},
\end{aligned}
$$

TABLE 2: The range of dimensionless parameters.

\begin{tabular}{lc}
\hline Dimensionless parameters and index properties & Values \\
\hline Penetration ratio $\left(P_{r}\right)$ & $0.125-0.5$ \\
Ratio of crushed zone radius to perforation radius $\left(R_{r}\right)$ & $2-4$ \\
The crushed-zone damage permeability ratio $\left(K_{r}\right)$ & $10-100$ \\
Porosity of skin zone $\left(\gamma_{s}\right)$ & $20 \%$ \\
Porosity of formation zone $\left(\gamma_{f}\right)$ & $25 \%$ \\
\hline
\end{tabular}

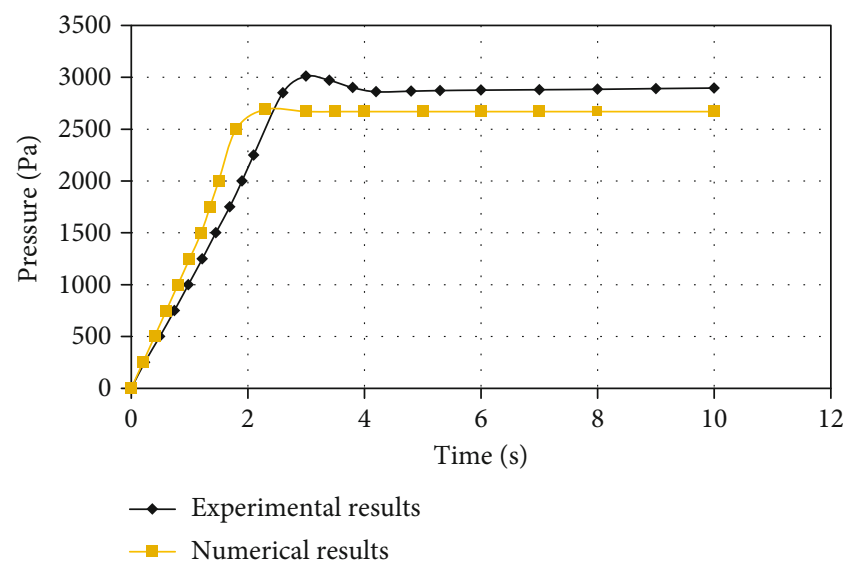

FIgURE 7: Comparison between experimental data and numerical results of the pressure buildup at the same flow boundary conditions $(Q=1 \mathrm{~L} / \mathrm{min}, v=0.95 \mathrm{mPa} \cdot \mathrm{s})$.

where $v_{j}$ indicates velocity components for $x, y$ and $z$ directions and $n_{x}, n_{y}$, and $n_{z}$ denote the medium thickness for the $x, y$, and $z$ directions.

Uniform mesh and cut mesh methods (Figure 6) were used to generate high-quality mesh. This configuration helped to predict a good-quality and high-density mesh close to perforation borders. 
TABLE 3: The relative effect of three dimensionless parameters on the crushed skin factor.

\begin{tabular}{|c|c|c|c|c|c|}
\hline$P_{r}\left(R_{r}=3, K_{r}=55\right)$ & $S_{w t}$ & $R_{r}\left(P_{r}=0.3125, K_{r}=55\right)$ & $S_{w t}$ & $K_{r}\left(P_{r}=0.3125, R_{r}=3\right)$ & $S_{w t}$ \\
\hline 0.125 & 7.27 & 2 & 10.6 & 10 & 2.2 \\
\hline 0.3125 & 16.4 & 3 & 16.4 & 55 & 16.4 \\
\hline 0.5 & 27.8 & 4 & 21.6 & 100 & 30.6 \\
\hline
\end{tabular}

TABLE 4: Twelve numerical runs.

\begin{tabular}{|c|c|c|c|c|c|c|c|c|}
\hline No & $P_{r}$ & $R_{r}$ & $K_{r}$ & $S_{w t}$ & $S_{w o t}$ & $\Delta P_{w t}(P a)$ & $\Delta P_{\text {wot }}(P a)$ & $\Delta P_{w o c}(P a)$ \\
\hline 1 & 0.3125 & 2 & 100 & 20.01 & 9.52 & 2032 & 1082 & 211 \\
\hline 2 & 0.125 & 3 & 10 & 1.23 & 1.14 & 217 & 208 & 104 \\
\hline 3 & 0.125 & 2 & 55 & 4.68 & 3.64 & 532 & 437 & 104 \\
\hline 4 & 0.5 & 2 & 55 & 18.08 & 8.78 & 1929 & 1079 & 276 \\
\hline 5 & 0.5 & 4 & 55 & 34.13 & 11.86 & 3351 & 1361 & 276 \\
\hline 6 & 0.5 & 3 & 100 & 51.31 & 13.28 & 4968 & 1491 & 276 \\
\hline 7 & 0.125 & 4 & 55 & 9.045 & 6.06 & 931 & 658 & 104 \\
\hline 8 & 0.5 & 3 & 10 & 4.63 & 3.62 & 799.6 & 607 & 276 \\
\hline 9 & 0.3125 & 4 & 10 & 3.77 & 2.18 & 550 & 395 & 221 \\
\hline 10 & 0.3125 & 2 & 10 & 1.74 & 1.68 & 370 & 365 & 211 \\
\hline 11 & 0.125 & 3 & 100 & 13.33 & 7.7 & 1323 & 808 & 104 \\
\hline 12 & 0.3125 & 4 & 100 & 40.77 & 9.4 & 3938 & 1071 & 211 \\
\hline
\end{tabular}

2.3. Statistical Procedure. Various methods for examining how different parameters may affect experimental results are applied by using Design of Experiments (DoE) software. The initial step in DoE is identifying independent variables and/or factors that may affect the experimental outcomes. The next step involves identifying the dependent variables and/or factors [31]. The experiments usually run based on different factor values or levels, such that each run features a combination pertaining to the specific factor value(s) or level(s) being investigated. In the present work, we used Design Expert software with BBD in designing the runs needed for statistical analysis. The Box-Behnken design (BBD) is described as a response surface methodology (RSM) design and requires only three levels in its experimental or numerical runs $[32,33]$.

The model is then statistically validated through analysis of variance (ANOVA) [34]. Based on these initial processes, three dimensionless parameters were investigated, including the ratio of penetration space to perforation length $P_{r}$, the ratio of crushed radius to perforation radius $R_{r}$, and the crushed-zone damage permeability ratio $K_{r}$ :

$$
\begin{gathered}
P_{r}=\frac{h}{L_{p} n}, \\
R_{r}=\frac{r_{c z}}{r_{p}}, \\
K_{r}=\frac{k_{f}}{k_{c z}} .
\end{gathered}
$$

Two boundary points were then selected, and one mid- point was determined by BBD for the intervals of the parameters, as presented in Table 2.

\section{Results and Discussion}

The comparison between the experimental and numerical results of the pressure buildup with the same flow boundary conditions is shown in Figure 7. The dimensions of the perforation geometry and the index properties are the same as those used in the experimental procedure (see Table 1). This research investigates a specific water flow rate $(1 \mathrm{~L} / \mathrm{min})$ that was injected into the sample to determine the differential pressure. The experimental data and numerical results are in good agreement.

The validation of numerical results with experimental ones has given full confidence in using the numerical model to conduct huge investigations by creating a crushed zone with different crushed perforation parameters, perforation length, and crushed zone radius. The relative effect of three dimensionless parameters on the crushed skin factor was investigated before conducting statistical analysis. The numerical results showed that the ratio of penetration space to perforation length $P_{r}$ and the crushed-zone damage permeability ratio $K_{r}$ significantly affect the crushed skin factor. In contrast, the ratio of crushed radius to perforation radius $R_{r}$ has a moderate effect on the crushed skin factor, as shown in Table 3.

Twelve numerical runs were performed and analyzed to obtain a suitable statistical analysis using the ANOVA analysis with the BBD model (Table 4).

Therefore, crushed perforation parameters are analyzed by using statistical analysis coupled with the numerical 

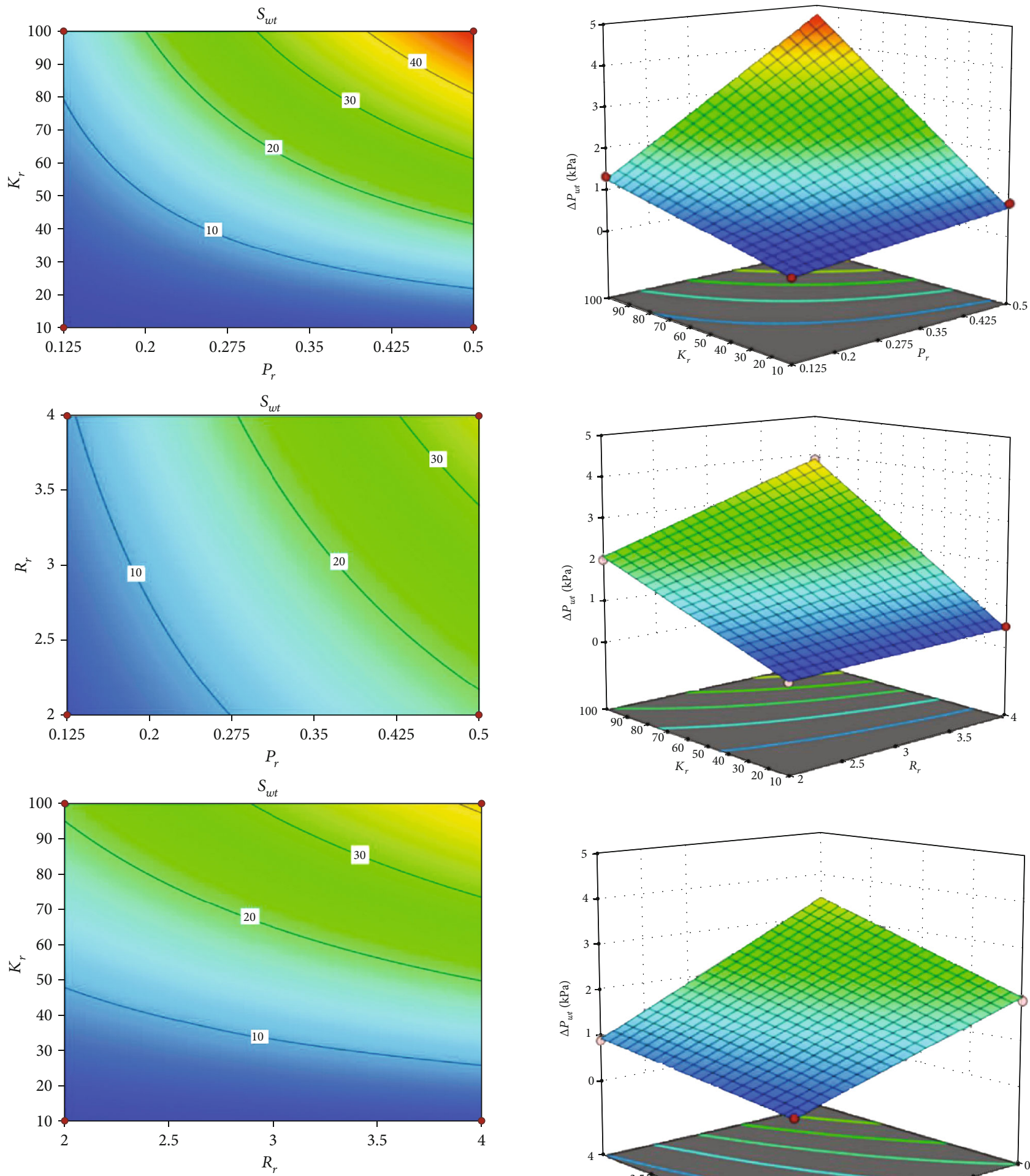

Figure 8: The dimensionless parameters' $\left(P_{r}, K_{r}\right.$, and $\left.R_{r}\right)$ interactions with each other, and their effect on crushed skin factor.

simulation model. This study provided two correlations from the statistical analysis, based on the numerical results. These correlations were used to determine the relative impact of each factor for the two scenarios on the crushed skin factor.
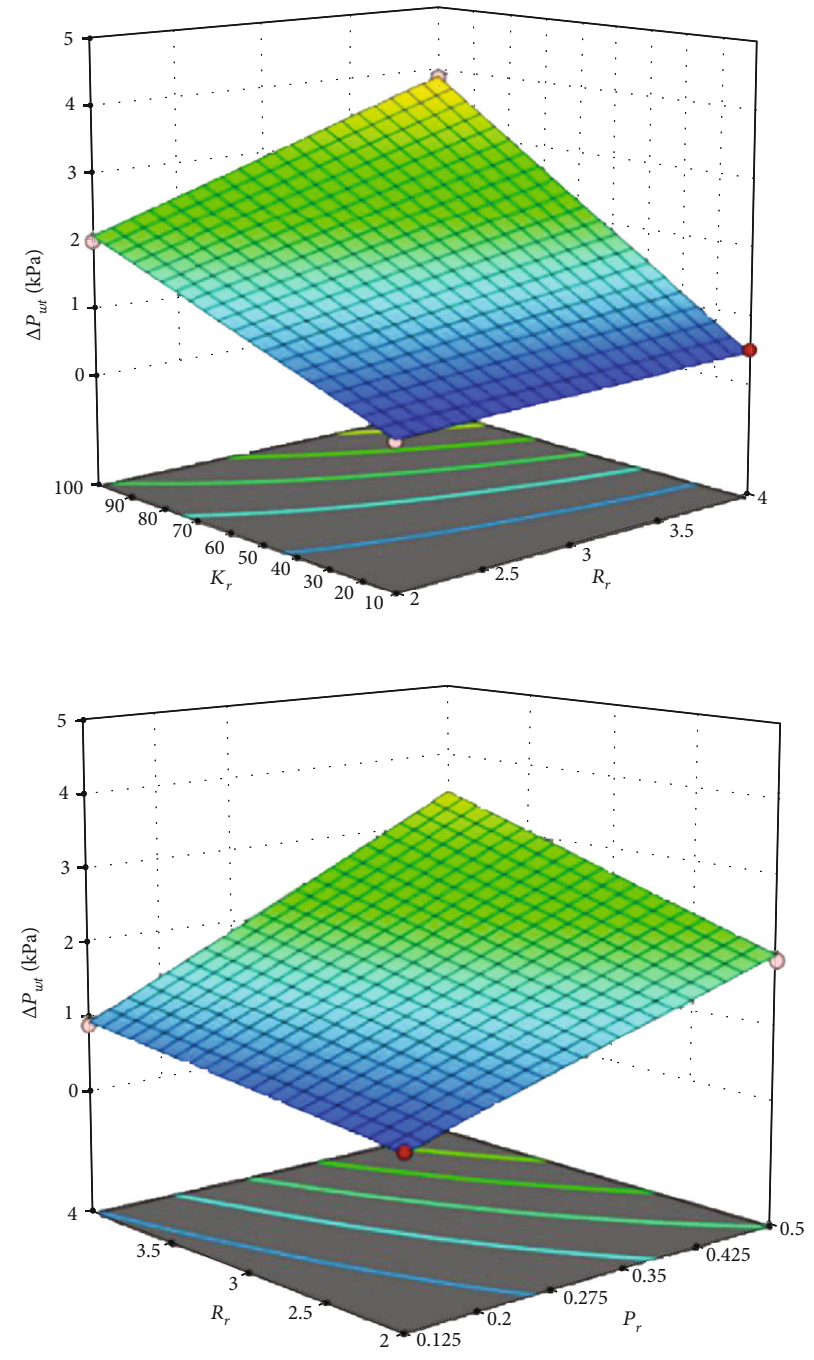

FIgURE 9: The dimensionless parameters' $\left(P_{r}, K_{r}\right.$, and $\left.R_{r}\right)$ interactions with each other and their effect on the pressure gradient for second scenario (with crushed tip) at boundary conditions of $Q=1 \mathrm{~L} / \mathrm{min}, \mu=0.001003 \mathrm{~kg} / \mathrm{m}-\mathrm{s}, r_{e}=91.44 \mathrm{~cm}, r_{w}$ $=3.81 \mathrm{~cm}, \quad r_{p}=0.635 \mathrm{~cm}, r_{c z}=1.27-2.54 \mathrm{~cm}, L_{p}=15.24-60.96 \mathrm{~cm}$, $h=30.48 \mathrm{~cm}, n=2-8, \theta=90^{\circ}, k_{f}=10^{-10} \mathrm{~m}^{2}, k_{c z}=10^{-11}-10^{-12} \mathrm{~m}^{2}$, $\gamma_{s}=20 \%$, and $\gamma_{f}=25 \%$. 


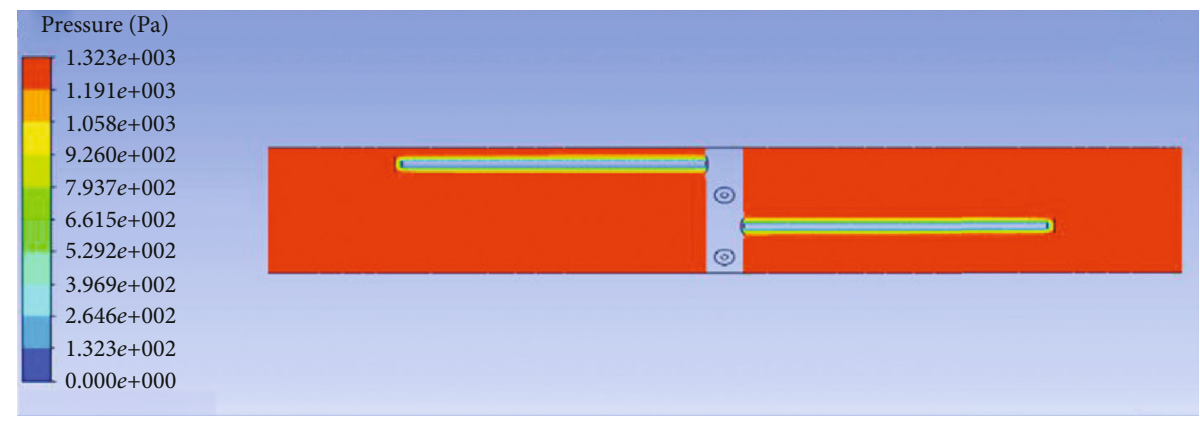

(a)

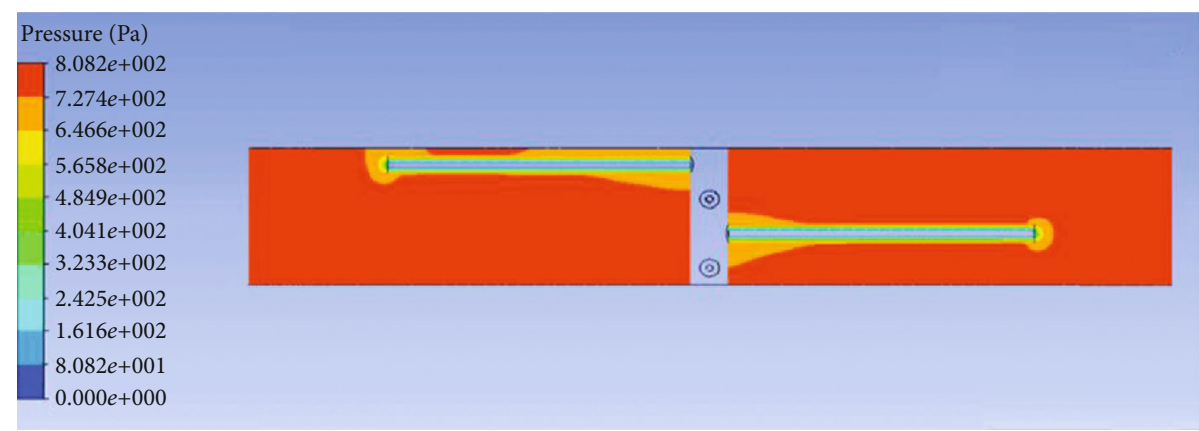

(b)

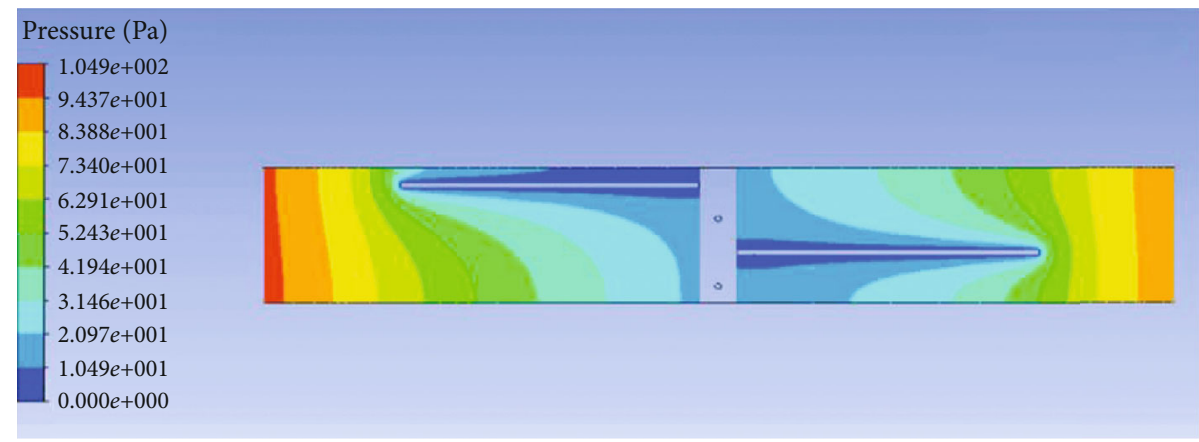

(c)

FIGURE 10: The distribution of the pressure gradient for three cases: (a) perforations with crushed tip, (b) perforations without crushed tip, and (c) ideal perforations without crushed zone at boundary conditions of $Q=1 \mathrm{~L} / \mathrm{min}, \mu=0.001003 \mathrm{~kg} / \mathrm{m}-\mathrm{s}, r_{e}=91.44 \mathrm{~cm}, r_{w}=3.81 \mathrm{~cm}$, $r_{p}=0.635 \mathrm{~cm}, r_{c z}=1.905 \mathrm{~cm}, L_{p}=60.96 \mathrm{~cm}, h=30.48 \mathrm{~cm}, n=4, \theta=90^{\circ}, k_{f}=10^{-10} \mathrm{~m}^{2}, k_{c z}=10^{-12} \mathrm{~m}^{2}, \gamma_{s}=20 \%$, and $\gamma_{f}=25 \%$.

$$
\begin{aligned}
& S_{w t}= 15.7-48.18 P_{r}-5 R_{r}-0.317 K_{r}+14.9 P_{r} * R_{r} \\
&+P_{r} * K_{r}+0.1076 R_{r} * K_{r}, \\
& S_{w o t}=-4.3+12.67 P_{r}+0.673 R_{r}+0.088 K_{r} .
\end{aligned}
$$

The results clearly indicate the crushed perforation parameters effects on both the crushed skin factor and pressure gradient values. The results show that crushed skin increases the pressure drop and thus contributes to a reduction in the productivity index. As illustrated in Figure 8, the value of the crushed skin factor increases with the increase of the penetration ratio $\left(P_{r}\right)$, the ratio of the crushed zone to perforation radius $\left(R_{r}\right)$, and crushed-zone damage permeability ratio $\left(K_{r}\right)$. From this, we can surmise that the interaction among these parameters has a marked effect on the crushed skin factor value, whereas the perforations without a crushed zone represent an ideal case that may or may not be reproducible in practice. Furthermore, based on the results, we can see that the pressure gradient is more affected by a high ratio for the three parameters. The perforation length makes a more significant contribution to pressure drop decreasing, and the higher crushed-zone damage permeability ratio with short perforations leads to pressure drop increases around the perforations, as shown in Figure 9. Also, the results show the significant effect of a large thickness of crushed zone with a high crushed-zone damage permeability ratio on the pressure gradient due to the frame's resistance around the perforations with a significantly high reduction in the permeability.

Moreover, the numerical results show a clear view of pressure distribution for the perforation with a crushed tip, without a crushed tip, and ideal perforations cases. For example, the pressure gradient for the three cases at dimensions' 

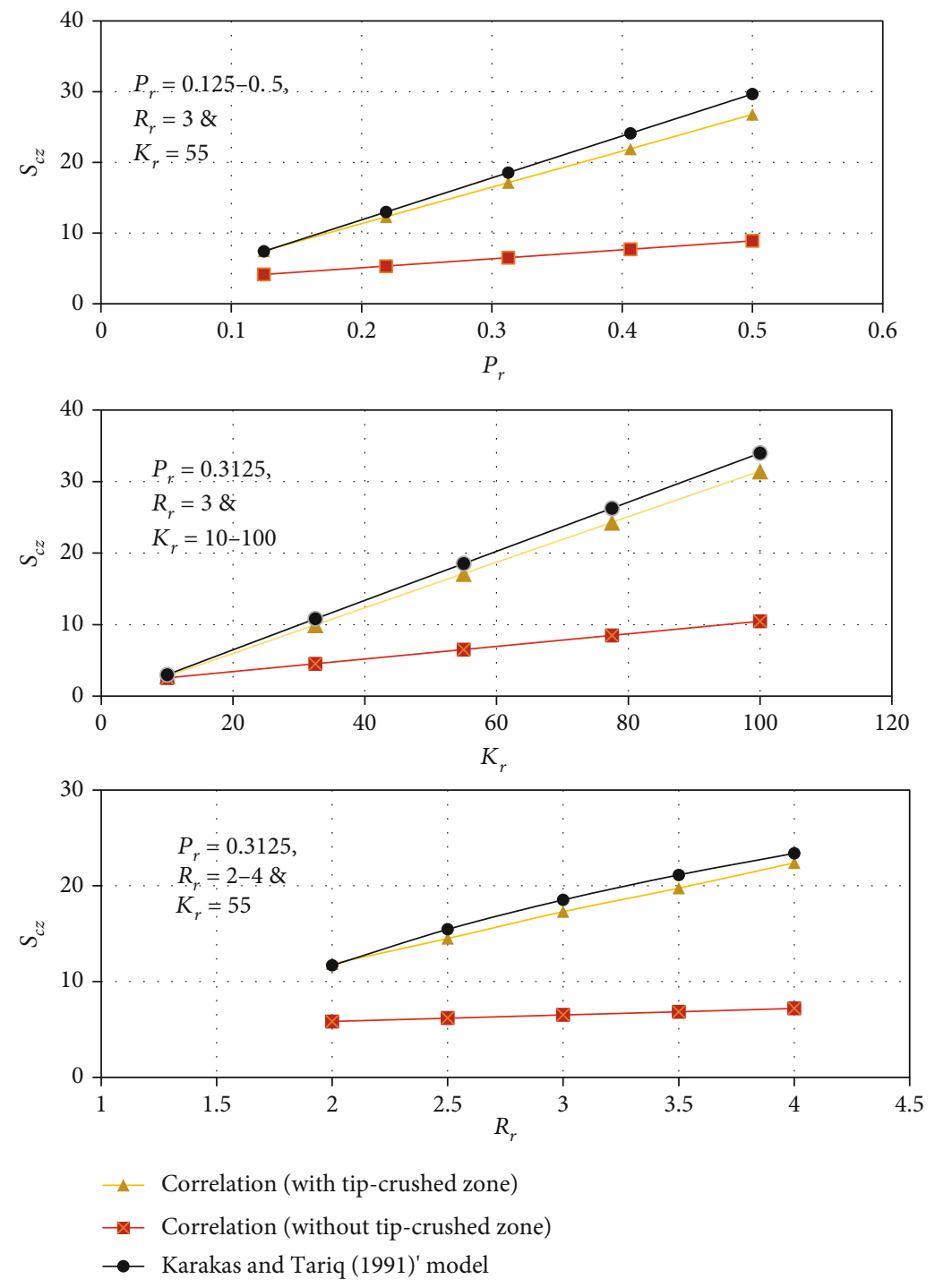

FIgURE 11: The comparison between the crushed skin factor results of two scenario correlations and the model of [14].

parameters values $\left(P_{r}=0.125, R_{r}=3\right.$, and $\left.K_{r}=100\right)$ is shown in Figure 10.

In order to compare and discuss the accuracy of the common models, one model by Karakas and Tariq [14] was selected and used to calculate the crushed skin factor without formation damage. The model was compared with two novel correlations for two scenarios. The comparison results show a comprehensive realization of the effect of three dimensionless parameters $\left(P_{r}, K_{r}\right.$, and $\left.R_{r}\right)$ on the crushed skin value and the deviation between the Karakas and Tariq [14] model and novel correlation for two scenarios.

The crushed skin factor results of the first correlation with a tip-crushed zone $\left(S_{w t}\right)$ showed a slight deviation with the previous model of Karakas and Tariq [14] while the crushed skin results of the second correlation without a tipcrushed zone $\left(S_{w o t}\right)$ demonstrated a large deviation for three dimensionless parameters, as shown in Figure 11. In general, the Karakas and Tariq [14] model applied to calculate the crushed skin factor shows a good convergence with the sec- ond scenario, so the model takes into consideration the effect of all frame resistance around the perforations. However, our CFD model gave almost identical results to the model if we assumed the length of the perforations was shorter than their length by a thickness of the crushed zone.

Also, the present study looks at the effect of permeability anisotropy in crushed zones on the skin factor with regard to the study's two scenarios. In the CFD simulations, the interaction effect between permeability anisotropy $\left(k_{c h} / k_{c v}=1-\right.$ $10)$ in the crushed zone and the crushed-zone damage permeability ratio $\left(K_{r}=1-100\right)$ has been investigated. As illustrated in Figures 12 and 13, there is a seeming increase in crushed skin factor when permeability anisotropy in the crushed zone is assumed. It is plausible that this rise's mechanism is related to nonradial flow near the perforation tunnel caused by permeability anisotropy at the crushed zone, particularly in cases of increased crushed zone thickness and perforation length. The results showed that the anisotropy in the crushed zone between $k_{c h} / k_{c v}=1-7.75$ has a 

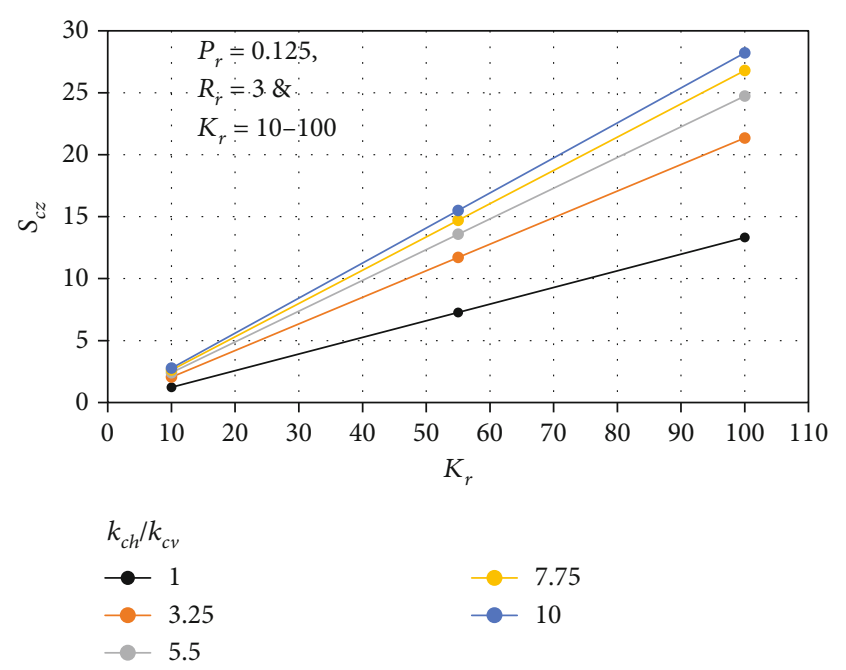

FIGURE 12: CFD results of crushed skin factor under the effect of permeability-anisotropy $\left(k_{c h} / k_{c v}=1-10\right)$ at the crushed zone for perforation with crushed tip scenario.
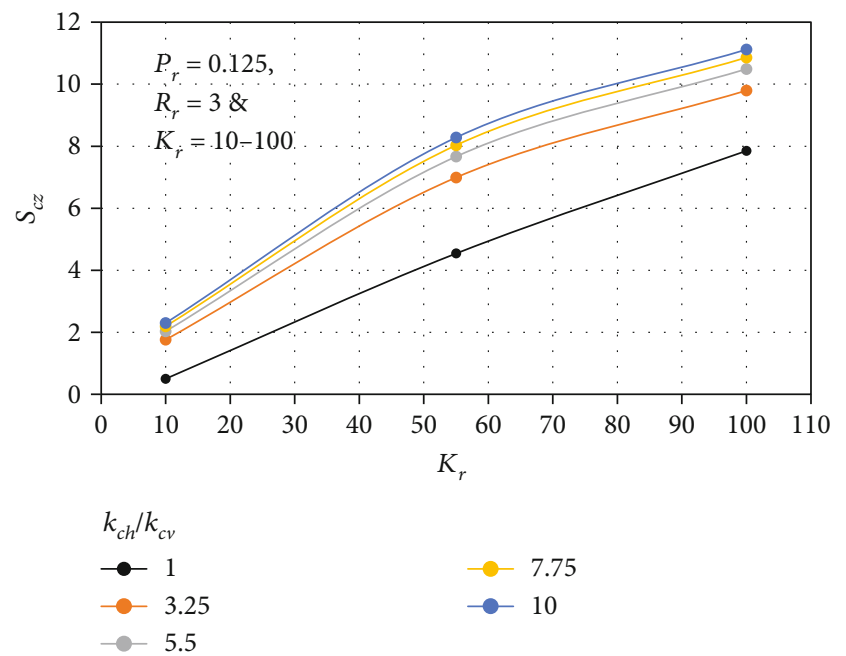

FIGURE 13: CFD results of crushed skin factor under the effect of permeability-anisotropy $\left(k_{c h} / k_{c v}=1-10\right)$ at the crushed zone for perforation without crushed tip scenario.

significant effect on the crushed skin factor, and then, its effect decreases, due to the domination of the horizontal flow. These outcomes showed that a better understanding of crushed zone anisotropy is needed, using the improvement of techniques for determining which factors affect perforated completions and to what extent.

\section{Conclusions}

The study was conducted in order to further investigate the accuracy of Karakas and Tariq's [14] model for crushed skin factor as well as to obtain new correlations which may be closer to reality, established on some assumptions. Based on the results of this investigations' analysis, the following conclusions can be summarized:
(1) The experimental data showed good agreement with the numerical model results used in this work to conduct more investigations

(2) The study showed a clear view of the effect of the three dimensionless parameters $\left(P_{r}, K_{r}\right.$, and $\left.R_{r}\right)$ on the crushed skin factor and pressure gradient

(3) The comparison of the simulations reveals that there is a significant difference between each of the two tipcrushed zone scenarios

(4) The numerical model gave almost identical results as for Karakas and Tariq's model, if the length of the perforations was assumed to be shorter than their real length by a thickness of crushed zone

(5) The differences between the two simulations' results show that the currently available model [14] for estimating the skin factor for vertical perforated completions needs to be improved, based on which of the two cases is closer to reality

(6) The study presented two novel correlations that give more than one option to calculate the crushed skin factor

(7) The outcomes of this study underscore the need to include the crushed zone anisotropy effect through the improvement of available models for determining the crushed skin factor

\section{Nomenclature}

$\vec{B}_{f}$ : Body force

$C_{2}$ : Inertial resistance factor

$h: \quad$ Formation thickness

$k_{c z}$ : Permeability of crushed zone

$k_{c h}$ : Horizontal permeability of crushed zone

$k_{c v}$ : Vertical permeability of crushed zone

$k_{d}$ : $\quad$ Permeability of damaged zone

$k_{f}: \quad$ Formation permeability

$K_{r}: \quad$ Permeability ratio

$L_{p}: \quad$ Perforation length

$n$ : $\quad$ Number of perforations (number of shots per foot)

$p$ : $\quad$ Pressure

$P_{r}:$ Penetration ratio

Q: $\quad$ Flow rate

$r_{c z}$ : Radius of crushed zone around perforation

$r_{e}: \quad$ Reservoir radius

$r_{p}: \quad$ Perforation radius

$R_{r}: \quad$ Ratio of crushed zone to perforation radius

$r_{w}: \quad$ Wellbore radius

$S_{c z}: \quad$ Skin due to rock crushed around perforations

$S_{d}: \quad$ Skin due to formation damage

$S_{h}$ : Skin due to horizontal flow effect

$S_{p}: \quad$ Skin due to ideal perforations

$S_{p d c}:$ Total perforation skin factor

$S_{v}: \quad$ Skin due to vertical converging effect

$S_{w b}: \quad$ Skin due to wellbore effect 
$S_{\text {wot }}: \quad$ Skin due to crushed zone without tip

$S_{w t}: \quad$ Skin due to crushed zone with tip

$t: \quad$ Time

$\vec{v}: \quad$ Velocity

$v_{j}$ : Velocity components for $x, y$, and $z$ directions

$\gamma: \quad$ Porosity

$\gamma_{f}$ : Porosity of formation zone

$\gamma_{s}: \quad$ Porosity of crushed zone

凶: $\quad$ Perforation angle

$\rho$ : $\quad$ Fluid density

$\overline{\bar{\tau}}$ : $\quad$ Stress tensor related to viscous flow

$\mu$ : $\quad$ Fluid viscosity

$\Delta_{n}: \quad$ Medium thickness

$\Delta p_{p d c}:$ Pressure drop due to total skin factor

$\Delta p_{\text {woc }}$ : Pressure drop (ideal perforations without crushed zone)

$\Delta p_{\text {wot }}:$ Pressure drop due to crushed zone without tip

$\Delta p_{w t}$ : Pressure drop due to crushed zone with tip

\section{Abbreviations}

ANOV: Analysis of variance

BBD: Box-Behnken design

CFD: Computational fluid dynamics

DAQ: Data acquisition

DoE: Design of experiments

RFC: Radial flow cell

RSM: Response surface methodology.

\section{Data Availability}

The data used to support the findings of this study are available from the corresponding author upon request.

\section{Disclosure}

The authors certify that this work is original, has not been published, and will not be submitted elsewhere for publication. Statements made herein are solely the responsibility of the authors.

\section{Conflicts of Interest}

The authors certify that they have no known competing financial interests that could have influenced the work reported in this manuscript.

\section{Acknowledgments}

This publication was also made possible by the grant NPRP10-0101-170091 from Qatar National Research Fund (a member of the Qatar Foundation).

\section{References}

[1] T. Alle and H. Worzel, "Productivity method of evaluating gun perforating," in Paper presented at the Drilling and Production Practice, New York, 1956.
[2] R. Krueger, "Joint bullet and jet perforation tests (progress report)," in Paper presented at the Drilling and Production Practice, New York, 1956.

[3] R. Krueger, "An overview of formation damage and well productivity in oilfield operations," in An Update. Paper presented at the SPE California Regional Meeting 1988, Long Beach, CAL, 1956.

[4] S. Tariq, "New, generalized criteria for determining the level of underbalance for obtaining clean perforations," in Paper presented at the SPE Annual Technical Conference and Exhibition, New Orleans, Louisiana, 1990.

[5] I. C. Walton, "Optimum underbalance for the removal of perforation damage," in Paper presented at the SPE Annual Technical Conference and Exhibition, Dallas, Texas, 2000.

[6] B. Grove, J. Harvey, and L. Zhan, "Perforation cleanup by means of dynamic underbalance: new understanding," SPE Drilling \& Completion, vol. 28, no. 1, pp. 11-20, 2013.

[7] R. P. Satti, R. White, D. Ochsner, O. Osarumwense, S. N. Zuklic, and T. Sampson, "From computerized tomography to CFD: production flow prediction in realistic perforation tunnels," in Paper presented at the SPE European Formation Damage Conference and Exhibition, Budapest, Hungary, 2015.

[8] R. P. Satti, R. White, D. Ochsner, O. Osarumwense, S. N. Zuklic, and T. Sampson, "New insights into optimizing perforation clean up and enhancing productivity with zinc-case shaped charges," in Paper presented at the SPE International Conference and Exhibition on Formation Damage Control, Lafayette, Louisiana, USA, 2016.

[9] R. Satti, S. N. Zuklic, D. Bale et al., "Advanced analysis of clean-up and productivity from perforated rocks," in Paper presented at the SPE Western Regional Meeting, Garden Grove, California, USA, 2018.

[10] J. Klotz, R. Krueger, and D. Pye, "Effect of perforation damage on well productivity," Journal of Petroleum Technology, vol. 26, no. 11, pp. 1303-1314, 1974.

[11] S. Locke, "An advanced method for predicting the productivity ratio of a perforated well," Journal of Petroleum Technology, vol. 33, no. 12, pp. 2481-2488, 1981.

[12] L. K. Thomas, C. E. Evans, R. G. Pierson, and S. L. Scott, "Well performance model," Journal of Petroleum Technology, vol. 44, no. 2, pp. 220-229, 1991.

[13] H. McLeod, "The effect of perforating conditions on well performance," Journal of Petroleum Technology, vol. 35, no. 1, pp. 31-39, 1983.

[14] M. Karakas and S. Tariq, "Semianalytical productivity models for perforated completions," SPE Production Engineering, vol. 6, no. 1, pp. 73-82, 1991.

[15] T. W. Bell, S. M. Tariq, and R. A. Sukup, Perforating, Richardson: Henry L. Doherty memorial fund of AIME, Society of petroleum engineers, 1995.

[16] T. Yildiz, "Assessment of total skin factor in perforated wells," SPE Reservoir Evaluation \& Engineering, vol. 9, no. 1, pp. 6176, 2006.

[17] D. Sun, B. Li, M. Gladkikh, R. Satti, and R. Evans, "Comparison of skin factors for perforated completions calculated with computational-fluid-dynamics software and the KarakasTariq semianalytical model," SPE Drilling \& Completion, vol. 28, no. 1, pp. 21-33, 2013.

[18] C. H. Yew and X. Zhang, "A study of the damage zone created by shaped-charge perforating," in the Low Permeability Reservoirs Symposium, Denver, Colorado, 1993. 
[19] M. Sarmadivaleh, A. Nabipour, M. S. Asadi, J. M. Sabogal Polania, and V. Rasouli, "Identification of porosity damaged zones around a perforation tunnel based on DEM simulation," in the ISRM International Symposium - 6th Asian Rock Mechanics Symposium, New Delhi, India, 2010.

[20] J. K. Pucknell and L. A. Behrmann, "An investigation of the damaged zone created by perforating," in the SPE Annual Technical Conference and Exhibition, Dallas, Texas, 1991.

[21] A. Nabipour, M. Sarmadivaleh, M. S. Asadi, J. M. Sabogal Polania, B. Evans, and V. Rasouli, "Evaluation of discrete element method for realistic modeling of reservoir rock," in the SPE Asia Pacific Oil and Gas Conference and Exhibition, Brisbane, Queensland, Australia, 2010.

[22] G. G. Craddock, J. Smith, and D. Haggerty, "Perforation crushed zone characteristics in a subsurface sandstone," in the SPE International Conference and Exhibition on Formation Damage Control, Lafayette, Louisiana, USA, 2018.

[23] S. Xue, X. Zhu, L. Zhang, S. Zhu, and G. Ye, "Research on the damage of porosity and permeability due to perforation on sandstone in the compaction zone," Computers, Materials \& Continua, vol. 51, no. 1, pp. 21-42, 2016.

[24] M. Ahammad, M. Rahman, L. Zheng, J. Alam, and S. Butt, "Numerical investigation of two-phase fluid flow in a perforation tunnel," Journal of Natural Gas Science and Engineering, vol. 55, pp. 606-611, 2018.

[25] M. J. Ahammad, M. A. Rahman, S. D. Butt, and J. M. Alam, "An experimental development to characterise the flow phenomena at the near-wellbore region," in ASME 2019 38th International Conference on Ocean, Offshore and Arctic Engineering, Glasgow, Scotland, UK, 2019.

[26] M. A. Rahman, T. Heidrick, B. Fleck, and M. Koksal, "Enhancement of the completion efficiency of perforation tunnels in petroleum wells," in ASME 2006 2nd Joint U.S.-European Fluids Engineering Summer Meeting Collocated With the 14th International Conference on Nuclear Engineering, Miami, Florida, USA, 2006.

[27] M. A. Rahman, "Scale-up of perforation process from laboratory model to bottom hole dimensions," Journal of Porous Media, vol. 11, no. 1, pp. 19-34, 2008.

[28] M. Rahman, S. Mustafiz, J. Biazar, M. Koksal, and M. Islam, "Investigation of a novel perforation technique in petroleum wells-perforation by drilling," Journal of the Franklin Institute, vol. 344, no. 5, pp. 777-789, 2007.

[29] M. Rahman, S. Mustafiz, M. Koksal, and M. R. Islam, "Quantifying the skin factor for estimating the completion efficiency of perforation tunnels in petroleum wells," Journal of Petroleum Science and Engineering, vol. 58, no. 1-2, pp. 99-110, 2007.

[30] L. Zheng, M. A. Rahman, M. J. Ahammad, S. D. Butt, and J. M. Alam, "Experimental and numerical investigation of a novel technique for perforation in petroleum reservoir," in the SPE International Conference and Exhibition on Formation Damage Control, Lafayette, Louisiana, USA, 2016.

[31] J. P. Davim, Design of Experiments in Production Engineering, Springer, Cham, 2016.

[32] G. E. Box and D. W. Behnken, "Some new three level designs for the study of quantitative variables," Technometrics, vol. 2, no. 4 , pp. $455-475,1960$.
[33] G. E. Box and D. R. Cox, "An analysis of transformations," Journal of the Royal Statistical Society: Series B (Methodological), vol. 26, no. 2, pp. 211-243, 1964.

[34] S. Ferreira, R. Bruns, H. Ferreira et al., "Box-Behnken design: an alternative for the optimization of analytical methods," Analytica Chimica Acta, vol. 597, no. 2, pp. 179-186, 2007. 